\title{
Entre celas: o encarceramento como sintoma de uma sociedade patológica
}

\author{
Between cells: incarceration as a symptom of a pathological society
}

\begin{abstract}
iD Osmar Veronese
Doutor em Modernización de las Instituciones y Nuevas Perspectivas en Derechos Fundamentales pela Universidad de Valladolid/Espanha, com diploma revalidado pela Universidade Federal de Pernambuco Professor do curso de Graduação em Direito e do Programa de Pós-Graduação Stricto Sensu em Direito (Mestrado e Doutorado) da Universidade Regional Integrada do Alto Uruguai e das Missões - URI Santo Ângelo/RS.Procurador da República - Ministério Público Federal osmarveronese@gmail.com
\end{abstract}

\begin{abstract}
Daiane Specht Lemos da Silva Mestre em Direito pela Universidade Regional Integrada do Alto Uruguai e das Missões - URI Santo Ângelo Pós-Graduada em Direito Penal Processual Penal - Faculdades Integradas Machado de Assis. Pós-graduanda em Direito Previdenciário - Faculdades Legale. Advogada daianespecht@hotmail.com
\end{abstract}

Resumo: As desigualdades sociais e o crescente aumento da criminalidade sinalizam uma catástrofe social que necessita ser enfrentada pelo Estado. Nessa perspectiva, o presente artigo objetiva discutir a criminalidade enquanto patologia social impulsionada pelas desigualdades, bem como a adequação e eficácia do tratamento realizado a partir do aprisionamento, na lógica dos condomínios e dos encarceramentos. A partir do método hipotético-dedutivo, o estudo propõe um olhar de três dimensões: primeiro, traça um panorama sobre as patologias do social; segundo, examina se a desigualdade social pode ser considerada uma patologia do social produtora da criminalidade; e, por fim, faz uma analogia entre estabelecimentos prisionais e condomínios privados, pensando no equívoco da segregação como proposta de cura das doenças de nosso tempo.

Palavras-chave: patologia social; sintoma; criminalidade; condomínio; estabelecimento prisional.

Abstract: Social inequalities and the increasing growth in crime rates point out a social catastrophe that needs to be faced by the State. In this perspective, the present article aims to discuss crime as a social pathology driven by inequalities. It also intends to debate the adequacy and effectiveness of the treatment provided in the imprisonment, considering the logic of condominiums and incarcerations. This study uses the hypothetical-deductive method. The investigation suggests a three-dimensional look: firstly, it sets out a panorama about the social pathologies; secondly, it examines whether social inequality can be considered a social pathology, which results in crime; and finally, it makes an analogy between prisons and private condominiums, considering the segregation misconception as a proposal for healing the illnesses of our times.

Keywords: social pathology; symptom; criminality; condominium; prison.

\section{Para citar este artigo}

ABNT NBR 6023:2018

VERONESE, Osmar; SILVA, Daiane Specht Lemos da. Entre celas: o encarceramento como sintoma de uma sociedade patológica. Prisma Jurídico, São Paulo, v. 20, n. 1, p. 81-99, jan./jun. 2021.

http://doi.org/10.5585/prismaj.v20n1.17069. 


\section{Introdução}

A divisão social, com grupos de indivíduos dominantes que excluem os demais do acesso aos bens essenciais à vida, sonegando a cidadania, é o signo de inúmeras sociedades contemporâneas. Há certa naturalização das desigualdades sociais, generalizando-se um discurso segundo o qual nem todos os indivíduos devem ser protegidos pelo Estado, o que gera abandono e ainda mais invisibilidade em relação a uma parcela significativa da sociedade, denotando uma patologia do social que necessita ser enfrentada e tratada.

Considerando que algumas das amostras dessa patologia social se revelam no aumento da criminalidade e na ausência de segurança, efeitos que prejudicam a normalidade social, o presente artigo aborda as patologias sociais fomentadas pelas desigualdades sociais, com enfoque na criminalidade, cuja cura, para alguns, passa por condomínios e encarceramentos. Objetiva-se discutir a criminalidade enquanto patologia social impulsionada pelas desigualdades, bem como a adequação e eficácia do tratamento realizado a partir do aprisionamento, abordando os estabelecimentos prisionais como produtos e produtores de exclusão social, traçando um paralelo com a autoexclusão vertida na lógica dos condomínios. Não passa despercebido que o estudo se apoia em autores com filiações teóricas diversas, em diálogo improvável, mas que, no contexto da abordagem, soa possível uma aproximação.

Em consonância com a temática apresentada, pelo estudo hipotético-dedutivo, com revisão bibliográfica, pretende-se analisar se a desigualdade social latente pode ser considerada uma patologia do social, bem como compreender se o estabelecimento prisional pode ser considerado tratamento suficiente para o sintoma da criminalidade. Para alcançar o objetivo proposto, o estudo inicia traçando um panorama sobre as patologias do social, depois examina se a desigualdade social pode ser considerada uma patologia do social fomentadora da criminalidade e, por fim, traçando um paralelo entre estabelecimentos prisionais e condomínios privados, aponta para a distopia da segregação como proposta de cura das doenças de nosso tempo.

\section{Patologias do social: a sintonia entre sofrimentos individuais e sintomas sociais}

"Cada doença possui sua história e sua antropologia. E, muitas vezes, estas exprimem reificações, individualização e naturalizações do sofrimento social retido em formas de vida que não podem mais ou ainda não podem ser reconhecidas." (Dunker, 2015). 
Assim como o indivíduo pode adoecer, percebe-se que a sociedade, como um todo, também pode ter patologias que acabam por influenciar a vida da coletividade, produzindo diversos sintomas sociais. A abordagem das possíveis "doenças" do social requer a análise do contexto histórico que ensejou as angústias e o desenvolvimento de síndromes. Nesse contexto, Christian Ing Lenz Dunker, ao abordar o mal-estar, examina o sofrimento e os sintomas das patologias e anomias ${ }^{1}$ do social.

Cuidar das patologias do social "[...] não significa necessariamente operar analogias entre sociologia e biologia a fim de trazer para o horizonte da vida social a compreensão da sociedade como um organismo a lutar contra doenças que poderiam enfraquecê-lo" (SAFARIE; DA SILVA JR; DUNKER, 2018, p. 10). A reflexão quanto às patologias do social refere-se à descrição quanto aos “[...] modos de participação social, e não uma reflexão sobre a sociedade como organismo saudável ou doente” (SAFARIE; DA SILVA JR; DUNKER, 2018. p. 11).

Para possibilitar a identificação das patologias sociais, pertinente descrever sobre o fato social e suas regras para a identificação do normal e do patológico. Nesse sentido, Émile Durkheim sublinha que os fatos sociais não podem ser confundidos com funções humanas regulares, tais como o ato de alimentar-se, dormir, raciocinar ou relacionar-se, eis que “[...] há em toda sociedade um grupo determinado de fenômenos que se distinguem por caracteres definidos daqueles que as outras ciências da natureza estudam" (DURKHEIM, 2007. p. 01).

O fato social consiste na forma de agir, de pensar ou sentir as representações exteriores individuais com "[...] força imperativa e coercitiva em virtude da qual se impõem a ele, quer queira, quer não" (DURKHEIM, 2007. p. 02). Compreende

[...] toda maneira de fazer, fixada ou não, suscetível de exercer sobre o indivíduo uma coerção exterior, ou ainda, toda maneira de fazer que é geral na extensão de uma sociedade dada e, ao mesmo tempo, possui uma existência própria, independente de suas manifestações individuais. (DURKHEIM, 2007, p. 13).

O direito existente nos códigos, por exemplo, possui forças além das consciências individuais, por dominar os indivíduos, o que exprime ser um fato social. Desse modo, os fatos sociais estão "[...] longe de serem um produto de nossa vontade, eles a determinam de fora; são como moldes nos quais somos obrigados a vazar nossas ações” (DURKHEIM, 2007, p. 29). O fenômeno definido como fato social depende então da generalidade, da coercitividade e da externalidade produzida de modo natural e dominador.

\footnotetext{
${ }^{1}$ Anomia do social é um termo desenvolvido por Emile Durkheim, que expressa a ausência, confusão ou não aplicação das normas sociais ou morais da sociedade (DURKHEIM, 2007).
} 
A dominação está presente em toda a sociedade, tanto nos indivíduos quanto nas estruturas, expressando a relação entre habitus e campo, de mútua interação, no qual a “[...] própria vontade de dominar é produto do campo que ela domina e faz reverter para ele todas as coisas" (BORDIEU, 1989, p. 84). Os fatos sociais refletem uma interferência naturalizada, em que a subordinação passa a ser um conjunto de práticas reiteradas com a “[...] mesma intenção objetiva, espécie de orquestração sem maestro, só se realiza mediante a concordância que se instaura" (BORDIEU, 1989, p. 86).

Ainda, os fatos sociais podem ser classificados como normais ou patológicos, e tal definição depende da sociedade sob análise, pois um fato pode ser considerado como normal para uma sociedade ao mesmo tempo em que para outra sociedade pode ser considerado patológico. Preconiza-se que não são em todas as ocasiões que a doença provoca desamparo, sendo que em alguns casos requer, tão somente, a adaptação. A patologia deve ser vista como um enfraquecimento do organismo, mas que não necessariamente precisa ser sofrida (DURKHEIM, 2007). Entretanto, para este estudo, entre o normal e o patológico, o sofrimento é visto como um fato social (DUNKER, 2015).

A patologia do social, nesta seara, traduz-se como uma questão de exclusão que rompe os laços sociais, que dispensa o diferente em uma sociedade dita normal. Aqui, a "[...] normalidade parece ser um horizonte referencial na conduta humana. Existiria uma forma de normalidade, um padrão, uma norma, que estabelece quem é normal e quem está "fora" da normalidade" (MANZI, 2017, p. 24). A noção de patologia não condiz com o desvio ou com a aplicação da lei, e sim em um aprendizado que "[...] pode constituir indicação preciosa de uma contradição posta em uma forma de vida pela qual ela ainda não pode ser reconhecida" (DUNKER, 2015, p. 25). Institui-se que o indivíduo deve ser insistente para a manutenção do estado normal, uma vez que

[...] o dever do homem de Estado não é mais impelir violentamente as sociedades para um ideal que lhe parece sedutor, mas seu papel é o do médico: ele previne a eclosão das doenças mediante uma boa higiene e, quando estas se manifestam, procura curálas. (DURKHEIM, 2007, p. 76).

A normalidade, sob esta análise, define se a sociedade possui ou não uma patologia. Ao tratar sobre patologias, faz-se necessário abordar os sintomas, haja vista ser através deles que exsurge o sofrimento, ou seja, o individual repercutindo no coletivo, e o coletivo abalando o individual (DUNKER, 2015). Contemporaneamente, o indivíduo busca incessantemente a felicidade, sem sopesar as consequências e/ou realidades a sua volta, assim, frequentemente “[...] emprega critérios equivocados, que ambicionam poder, sucesso e riqueza para si mesmos 
e os admiram nos outros enquanto menosprezam os verdadeiros valores da vida" (FREUD, 2010, p. 41).

A patologia, de certa forma, pode ser definida como uma forma de sofrimento que pode ser superada (MANZI, 2017). Eventualmente pode resultar na incapacidade, quando todos os indivíduos pertencentes à sociedade não conseguirem suplantar a problemática, pela ausência de recursos sociais (SIMIM, 2015). Quando um fato social foge de sua órbita da normalidade passa a ser uma ameaça à sociedade, originando a patologia (DURKHEIM, 2007). Habitualmente, “[...] a vida, tal como nos é imposta, é muito árdua para nós, nos traz muitas dores, desilusões e tarefas insolúveis. Para suportá-la, não podemos prescindir de lenitivos" (FREUD, 2010, p. 60).

Toda a sociedade possui patologias, algo inerente ao contínuo processo de socialização, uma vez que o sujeito socializa pela enunciação das normas e pelos seus sofrimentos reconhecidos. Os “" [...] conceitos utilizados para a compreensão do desenvolvimento individual, como saúde e doença, poderiam ser aplicados às sociedades complexas, aproximando suas situações de crise a processos de adoecimento" (SAFARIE; DA SILVA JR; DUNKER, 2018, p. 13). Por não ser “[...] mau definir épocas históricas pelo tipo de 'demônios íntimos' que as assombram e atormentam" (BAUMAN, 2011, n.p.), pode-se dizer que um dos males ou patologias sociais atuais é a exclusão, que fere e machuca o outro indiscriminadamente.

O sofrimento, contudo, não necessariamente configura uma patologia, pois há patologias sem padecimento, ademais "[...] o sofrimento possui uma estrutura transitiva, pois nele indeterminam-se quem sofre e quem está reconhecendo o sofrimento daquele que sofre" (DUNKER, 2015, p. 27). No sentido patológico do social, o sofrimento pende de "[...] um afastamento de casuísmos para interpretar o conteúdo 'universal', que exprima um sintoma de um tempo e de uma sociedade, impregnados de historicidade, mas que resistem a uma mera consideração particular" (CAMPELLO, 2017, p. 21).

A existência da patologia produz sintomas, que funcionam como "[...] poderosos veículos de identificação, pois formam-se, em parte, por identificações negadas, abolidas ou aposentadas. É aqui que o sintoma organiza simbolicamente demandas com as mais diferentes articulações do imaginário" (DUNKER, 2015. p. 26). Os “[...] sintomas produzem mais ou menos sofrimento de acordo com a forma da vida na qual emergem" (DUNKER, 2015, p. 76).

Não estamos programados para a felicidade (FREUD, 2010) e por isso o sofrimento pode ser resignado de modo individual ou coletivamente. Quando afeta o ser individual causa "[...] um efeito social bem delimitável por sentimentos que lhe seriam atinentes: piedade e culpa, vergonha e desamparo, indiferença e ressentimento" (DUNKER, 2015. p. 26). O 
sofrimento causado por patologias sociais demonstra ser um entrave à realização e reconhecimento, pois impede a liberdade do indivíduo, "[...] um impedimento de autoafirmação, de autorrespeito e de autoestima que pode levar a uma vacuidade ou esvaziamento de si” (MANZI, 2017).

Para o sujeito, o tempo é de inconsciência e culpa, pois se encontra perdido em meio aos sentimentos de "[...] servidão e esvaziamento, que o acorrenta à repetição de uma mesma rotina, na qual a realização da fantasia é parasitada pelo super eu e sua voz imperativa" (DUNKER, 2015, p. 38). Aceitam-se as formas de sofrer, sem perceber, pelo fato de que o sofrimento se tornou natural (MANZI, 2017). Surge assim, “[ [... a tendência de segregar do eu tudo que possa se tornar fonte de semelhante desprazer, de lançá-lo para fora, de formar um eu de prazer, ao qual se contrapõe um exterior desconhecido, ameaçador" (FREUD, 2010, p. 47).

O sofrer individual “[...] se expressa em falas únicas, de preferência em primeira pessoa. Por isso é importante jamais separar o sofrimento individual dos movimentos sociais que lhe deram origem (DUNKER, 2015, p. 26). Dessa forma,

É um erro supor, de acordo com aquele velho antropomorfismo sociológico, que "o
social sofre". Um "grupo sofre", "uma comunidade sofre", "uma família sofre". O que
queremos dizer com tais afirmações? Que há um sofrimento por identificação, um
sofrimento sob transferência, um sofrimento contagioso, mas que, ao fim e ao cabo, é
uma experiência tão individual quanto a dor? O ponto-chave aqui é o fato de o
sofrimento ser uma experiência compartilhada e coletiva. Os atos de reconhecimento
ou de desconhecimento transformam a experiência real do sofrimento (DUNKER,
2015. p. 26).

Em suma, quando a sociedade está em um processo de anormalidade instauram-se as patologias do social, as quais produzem sintomas e sofrimentos individuais. Embora o sofrimento seja individual, a experiência é coletiva, e as consequências da patologia atingem os demais componentes da sociedade. Ao mesmo tempo em que as patologias podem ser fatores de evolução das sociedades, os modos de agir não saudáveis precisam estar controlados para não provocarem consequências devastadoras, pois quando naturalizadas passam a ter poderes autodestrutivos.

\section{Aumento da criminalidade como sintoma da patologia desigualdade social}

"A globalização do capital gerou também uma globalização das maneiras de sofrer." (Dunker, 2015).

A humanidade experimentou inúmeros avanços e profundas mudanças nos últimos anos, impactada pela crescente influência do capitalismo na regência da economia e das vidas. Como 
consequência, surgem para o indivíduo - junto com a imposição de crescimento social constante, de conquistas econômicas urgentes, da necessidade em ser reconhecido e incluído em um grupo social - as patologias do social, novos mal-estares, sofrimentos e sintomas que acometem a coletividade e precisam ser enfrentados. No enfoque do presente estudo, as desigualdades sociais apresentam-se como uma patologia e o aumento da criminalidade como um de seus sintomas.

Durante séculos o capitalismo foi (e ainda é) tratado como "vilão", pelo fato de que em nome da aquisição de riquezas e acumulação de bens foram legitimadas "[...] as deportações, os massacres, o trabalho forçado, a escravidão" (FANON, 2015, p. 52), contexto que gera graves patologias e o consequente sofrimento da coletividade envolvida. O capitalismo, assim, incorpora uma forma individualizada de transformação e autotransformação do ser da transição econômica pela “[...] autonomização da produção, por meio do salário e da forma-mercadoria” (DUNKER, 2015, p. 90). Em resumo, somos uma sociedade de consumo, que "[...] propõe a todos a igualdade de direitos, principalmente por referências imaginárias, ao mesmo tempo em que marca diferenças estabelecidas pelo acesso ao consumo que vão da exclusão à exclusividade" (VERONESE; VERONESE, 2018, p. 635).

Há uma "[...] violência simbólica que encobre, distorce e permite a legitimação da dominação social no capitalismo tardio" (SOUZA, 2018, p. 30), que classifica e desclassifica as classes sociais, indiscriminadamente e sem piedade. A naturalização de atos e ações corporifica a desigualdade social e impede a observação com perspicácia da realidade social, o que permite "[...] ver a pobreza e a miséria de muitos e desconhecer as causas que produz esse estado" (SOUZA, 2018, p. 32).

Uma das características marcantes que o capitalismo produziu nas sociedades é a divisão social, que permite a existência de classes positiva e negativamente privilegiadas, tanto de capital econômico como de capital cultural (SOUZA, 2009). A economia se tornou capaz de determinar a vida dos indivíduos, pela perspectiva de que " [...] a ética protestante e o espírito do capitalismo, produzem o tipo de indivíduo que lhes convém: plástico, moldável, flexível, disciplinado, autocontrolado, responsável por si próprio, orientado para o futuro" (SOUZA, 2018, p. 112 - 113).

Tais seres moldados pelas perspectivas capitalistas atuam como produções simbólicas e, enquanto "[...] desprovidos de capital econômico e cultural, mais dependentes" (BORDIEU, 1989, p. 197). A divisão social representa, assim, a introdução de classes dominantes e dominadas, tendo em vista que são por meio das cotidianas estruturas, estruturantes e estruturadas que ocorre a contribuição para ser assegurada a dominação de uma classe sobre 
outra classe, uma violência simbólica que oportuniza a domesticação dos dominados (BORDIEU, 1989, p. 11).

A domesticação representa a naturalização da distinção de classes superiores com poder sobre as classes inferiores. A naturalização das desigualdades sociais toma proporções significativas, pois mesmo inexistindo respeito e reconhecimento a esses indivíduos dominados, pela ausência de consciência das vítimas, aceitam a “[...] precariedade como legítima e até merecida e justa, fechando o círculo do que gostaria de chamar de naturalização da desigualdade abissal como a da sociedade brasileira" (SOUZA, 2018, p. 222). Portanto,

\begin{abstract}
As causas da desigualdade e da ausência de reconhecimento social são, por definição, invisíveis a olho nu. Ainda que a pobreza e a miséria material sejam facilmente perceptíveis e reconhecíveis, as causas e precondições que as tornam possíveis $e$ socialmente legitimadas não o são. Esta é a razão última do fato historicamente invariante de que toda desigualdade existencial, política e material tenha que ser acompanhada por mecanismos simbólicos que mascaram e tornam opacas suas causas sociais. A reprodução da desigualdade material em todas as suas dimensões econômica cultura e política - pressupõe o sistemático desconhecimento/encobrimento, produzido e reproduzido simbolicamente, de suas causas efetivas (SOUZA, 2009, p. 91).
\end{abstract}

Mesmo sem enfrentar os motivos que geram as desigualdades sociais, percebe-se a naturalização da divisão social, sendo um “[...] mal-estar genérico, derivado das transformações sociais inspiradas pelo capitalismo tardio, e os sintomas específicos como a drogadição, a depressão, o pânico e a anorexia" (DUNKER, 2015, p. 66 - 67). A desigualdade ao ser definida como uma patologia do social funciona "[...] como uma desregulação sistêmica que viola o pacto social da 'boa convivência'” (DUNKER, 2015).

Pela patologia da desigualdade social, os indivíduos buscam "[...] a proteção mais imediata contra o sofrimento que pode resultar das relações humanas ... a solidão voluntária, o distanciamento em relação aos outros" (FREUD, 2010. p. 65). Somos levados a evitar a realidade a fim de evitar o sofrimento, por isso “[...] o êxito dos tóxicos na luta pela felicidade e no afastamento da desgraça é tão apreciado como benefício que tanto indivíduos quanto povos lhe concederam um lugar fixo na sua libidinal” (FREUD, 2010, p. 67).

O pacto social existente nas sociedades, que convive com as desigualdades sociais, também permite as violências simbólicas para cimentar a dominação entre as classes, de modo que, "[...] quanto mais difícil for o exercício da dominação direta, mais e mais precisar-se-ia de formas mascaradas de dominação" (SOUZA, 2018, p. 77). A relação entre a pobreza e a violência, pode ser exemplificada por uma ruptura do pacto social relacionada com o consumismo entre ricos e pobres. Em sua obra, Dunker (2015) apresenta como uma violação do pacto social o documentário de Eduardo Coutinho, Boca de Lixo, produzido em 1993. 
Ao comentar sobre o documentário, Dunker descreve os indivíduos dos lixões como “[...] vidas em situação de precariedade, na qual pequenos sonhos e a capacidade de imaginar um futuro melhor aparecem como despropósitos desmentidos" (DUNKER, 2015. p. 63). O autor observa que tais indivíduos “[...] retratam a ordem e o caráter sistemático em uma situação na qual supõem-se anomia e efeitos radicais da exclusão" (DUNKER, 2015, p. 63). Seguindo essa lógica, é possível fazer uma analogia com os manicômios, prisões e conventos, que quando criados tinham o intuito primordial de limpar os "indesejados" da sociedade, da mesma forma que os lixões funcionam como uma forma de excluir os "improdutivos" ou aqueles que não conseguiram "acompanhar o desenvolvimento".

Por inexistir a preocupação em resolver o problema do outro, muitos indivíduos procuram resolver sozinhos seus problemas, pelo autoisolamento, uma vez que, “[...] contra o temido mundo externo não é possível defender-se de outra maneira senão por alguma espécie de afastamento, caso se queira resolver essa tarefa por si mesmo" (FREUD, 2010. p. 65). Ademais, muitas vezes, quando o indivíduo em sofrimento busca auxílio do outro, este é fadado ao declínio, pois a preocupação existente refere-se a uma solução rápida e simplificada para o problema individual, por isso o

[...] imperialismo farmacológico impõe uma ditadura do silêncio acerca da dor: a mesma receita repetida inúmeras vezes, não é preciso escutar, só prescrever a camisa de força química. "Os Copiadores de Receita”, como chamava Estamira (2004) os psiquiatras burocratas simplificam seu trabalho e responsabilidade à administração de modos de controle dos corpos anestesiados (VERONESE; VERONESE, 2017. p. 84).

A partir dos exemplos acima citados, como a "limpeza social" e "anestesia dos doentes", é possível observar que a sociedade busca soluções rápidas e simplificadas para problemas complexos e, em razão disso, os resultados não são exitosos e os problemas reais são encobertos.

O processo social de inclusão e exclusão é, muitas vezes, deliberadamente ignorado. Busca-se encontrar culpados determinados pela existência da discriminação de classes, enquanto se sabe que todos os componentes da sociedade possuem um pouco de culpa. Muitos brasileiros condenados ao abandono desde antes de nascer, têm a consciência da necessidade de inclusão social, mas não compreendem que é insuficiente querer apenas uma integração subalterna destes indivíduos, pois “'[...] eles não querem ser apenas pintores de nossas paredes, mecânicos de nossos carros, engraxates de nossos sapatos. Eles querem o que os nossos filhos querem: internet, música, arte [...]” (SOUZA, 2009, p. 98).

Pela inclusão social ser de difícil realização, pois o Estado não detém o total controle da situação, compreende-se a desigualdade social como uma grave patologia social, causadora de 
vários sintomas. Para exemplificar a relação entre causas e sintomas da patologia do social, pode ser destacado os seguintes casos: os filhos rebeldes (sintoma) podem ser consequência da existência de uma família desestruturada (patologia); o fracasso escolar (sintoma) pode ser motivado pela ausência de capital cultural (patologia) (DUNKER, 2015), assim como o aumento da criminalidade (sintoma) pode ser considerado como uma das consequências de uma sociedade extremamente desigual, mas naturalizada (patologia).

O crescente aumento da criminalidade expõe, com ênfase, as classes vulneráveis, que, mesmo quando a sociedade se apresenta como normal, são esquecidas enquanto classe (SOUZA, 2009). A desigualdade social expõe que "[...] a violência é um falso universal erigido em prática discursiva de extração de mais-de-gozar" (DUNKER, 2015, p. 61). Conforme Souza (2009), ao julgar a violência como um reflexo da reprodução da desigualdade e da exclusão social, percebe-se que essa classe abandonada,

[...] mesmo sofrendo as consequências de viver sob condições de vida as mais desumanas possíveis - em meio à miséria material, à ameaça permanente de violência física e ao não reconhecimento social -, tende a viver seu sofrimento como sendo coisa habitual, componente inevitável de sua existência (SOUZA, 2009, p. 303).

A naturalização da desigualdade social não é tema atual. $O$ que se altera, contemporaneamente, é a forma de distinguir e excluir as classes sociais. O que antes era dividido pela violência institucionalizada da autoridade impessoal, de poder se sobrepor pela enunciação, no qual bastava só a presença (DUNKER, 2015), hoje é visualizado materialmente, pelo fato de que os indivíduos em situação de vulnerabilidade encontram-se excluídos do restante da sociedade tanto por barreiras simbólicas quanto por barreiras físicas, como muros ou celas dos estabelecimentos prisionais.

Pela necessidade de segurança, tem-se a falsa ideia de que apartar de si o diferente é a solução mais eficiente para a fixação de uma sociedade "saudável". A ilusão que se possui do alcance da felicidade pelo isolamento deriva-se dos juízos de valor dos indivíduos em apoiar seus desejos em seus falsos argumentos (FREUD, 2010). Engana-se quem pensa que entre os muros das casas ou condomínios há segurança (DUNKER, 2015), do mesmo modo que se mostra ardilosa a concepção de que a mera segregação do indivíduo diminuirá a violência.

A desigualdade, enquanto patologia do social, tem forte relação com a violência e com o aumento da criminalidade (sintomas patológicos que podem ou não causar sofrimentos), contribuindo para um contexto de descontrole, em que os órgãos responsáveis pela segurança não são capazes de conter a criminalidade por si só. No contexto brasileiro, pode-se determinar 
que o crime, de tão habitual, desestabilizou a ordem social, resultando em altos índices de encarcerados no país, o que evidencia a existência de uma grave patologia.

$\mathrm{O}$ aumento da população prisional brasileira pode ser comprovado pelos dados disponibilizados pelo Departamento Penitenciário Nacional - Ministério da Justiça e Segurança Pública. Extrai-se do relatório que "[...] entre os anos de 2000 e 2017, a taxa de aprisionamento aumentou mais de $150 \%$ em todo país. Em junho de 2017, o Brasil registrou 349,78 pessoas presas para cada 100 mil habitantes" (LEVANTAMENTO NACIONAL DE INFORMAÇÕES PENITENCIÁRIA, 2017, p. 12).

A patologia social pode ameaçar o pacto social existente de cumprimento da lei por meio do poder como violência desmedida (DUNKER, 2015). A não compreensão ou a inexistência de normas pode ser definida como uma anomia e "[...] é o pior que pode acontecer às pessoas em sua luta para dar conta dos afazeres da vida. As normas capacitam tanto quanto incapacitam, a anomia anuncia a pura e simples incapacitação" (BAUMAN, 2011, n.p.). Assim, pode-se afirmar que o crescente aumento da criminalidade e da insegurança é um dos sintomas da patologia social chamada desigualdade social. Contudo, em vez de buscar tratar suas doenças de forma definitiva, a sociedade acinte em buscar soluções rápidas para patologias em "estados mais avançados", ou seja, busca obter segurança e controlar o mal-estar e sofrimento sem tratar as causas da doença.

\section{Analogia entre a lógica dos condomínios e os estabelecimentos prisionais}
"Ao entrar em um desses modernos condomínios, projetados com a mais tenra engenharia urbanística, temos o sentimento pacificador de que enfim encontramos alguma ordem e segurança. Rapidamente nos damos conta de que há ali uma forma de vida na qual a precariedade, o risco e a indeterminação teriam sido abolidos." (Dunker, 2015).

A sociedade deseja segurança e requer proteção do Estado, contudo, com o crescente aumento da criminalidade, verifica-se a insuficiência estatal e a busca de outras medidas para proteger-se. Uma das soluções construídas foi o isolamento com seus semelhantes, em meio a muros altos que resplandecem, em tese, poder e confiança, confinam os considerados bons e impedem que os invasores ingressem naquele espaço privilegiado, uma espécie de território sem riscos. Razoável entender que o isolamento é produto de "[...] uma sociedade de massas, tipicamente urbana, cada vez mais enclausurada entre muros" (VERONESE; VERONESE, 2018, p. 632).

O descontrole social em razão da constante ocorrência de crimes indica que há patologias que necessitam ser tratadas. Ao notabilizar que as patologias do social podem 
repercutir no individual, e que a desigualdade social é uma patologia que fomenta a criminalidade, que afeta significativamente a normalidade da sociedade, é preciso considerar a necessidade de tratamentos que visem à restauração e o equilíbrio social.

A transição social ocorrida, de uma sociedade sólida para uma líquida, cujas características principais são os avanços tecnológicos e científicos, possui como alicerces, "[...] a velocidade, o hibridismo e a imaterialidade - por relação a categoria da cidade" (SILVA, 2007, s/p). As sociedades não lograram êxito, e na maioria das vezes não tentaram, “[...] homogeneizar e generalizar, em medida significativa, um tipo humano para todas as classes como uma precondição para uma efetiva e atuante ideia de cidadania” (SOUZA, 2018, p. 199).

A nova perspectiva de cidade traça intensamente uma divisão social, no qual os indivíduos que conseguiram se adaptar às novas demandas e tornaram-se produtivos estão de um lado, enquanto que os tachados como "inadaptados" tendem ao "[...] abandono, a uma crescente e permanente marginalização" (SOUZA, 2018. p. 211). Tais imposições individualizadoras criam "[...] um certo tipo de indivíduo e de comportamento individual e condenam todas as outras formas possíveis ao esquecimento e ao estigma da pré-modernidade, do delinquente e do marginalizado" (SOUZA, 2009, p. 108 - 109).

As conturbações sociais representam com magnitude a liquidez da contemporaneidade, em que o medo e a aflição fazem parte do cotidiano dos indivíduos (SILVA, 2007), e a ferrenha divisão classista existente expressa preconcepções discriminadoras e excludentes. Com isso, o indivíduo pertencente ao "[...] bairro, bem afastado do centro, é conhecido como um dos mais miseráveis e perigosos da cidade. A infraestrutura é péssima o suficiente para desafiar qualquer ideia de cidadania e dignidade" (SOUZA, 2009. p. 243).

A naturalização da desigualdade faz com que o status de cidadão seja reconhecido apenas para uma determinada parcela da sociedade, tornando certos grupos e indivíduos invisíveis para o sistema (SOUZA, 2009). O isolamento tem sido utilizado como uma forma de proteção, como uma resposta à sensação de insegurança, a exemplo dos condomínios, que seguem uma lógica de aprisionamento inversa ao impedir que os "outros" ingressem no território normalizado.

A insegurança é tratada de duas formas: pelo isolamento individual (condomínios) ou pela exclusão (encarceramento). Contudo, tais respostas demonstram-se insuficientes pela complexidade dos problemas. A contemporaneidade, líquida e fluida, demonstra facilidade nas trocas, e tudo se tornou substituível, inclusive as relações sociais, o que também acabou por naturalizar as desigualdades sociais, uma vez que o excesso de "individualidade" deixa pouco espaço para a alteridade. Junto com o novo plano líquido social, veio a insegurança e o medo. 
Hoje, segundo Bauman (2011, n.p.), é "[...] tempo de cadeados, cercas de arame farpado, ronda dos bairros e vigilantes".

Neste sentido, equiparam-se a lógica dos condomínios e a dos estabelecimentos prisionais, pois ambos são instrumentalidades que, visando garantir segurança à sociedade, excluem o "indesejado. A chamada lógica do condomínio transforma os

[...] problemas relativos à saúde pública, mental e geral, em meros problemas de gestão. Assim, a lógica do condomínio replica de maneira atualizada o impasse entre a apreensão falsamente universal de um particular e uma apreensão falsamente particular de um universal. (DUNKER, 2015, p. 29).

Em relação aos condomínios, os indivíduos que estão inseridos nestes espaços de isolamento e proteção representam a classe privilegiada da sociedade, pensando ter expulsado a violência para os “outros" (SOUZA, 2009). Os vulneráveis ficam à margem dos condomínios, impedidos de ingressar nos territórios restritos onde, em tese, se pode “[...] livremente exercer a convivência e o sentido de comunidade entre iguais. Um retorno para a natureza, uma vida com menos preocupação, plena de lazer na convivência de semelhantes" (DUNKER, 2015. p. 34).

Simbolicamente, os condomínios representam mais do que o isolamento individual por meio de muros altos em que apenas os "escolhidos" conseguem ingressar em seus portões (DUNKER, 2015), materializando a separação dos corpos que merecem proteção daqueles que não a merecem. Confirma-se, com isso, a crença na legitimação e merecimento social, o que autoriza a "[...] continuação da reprodução de uma sociedade que "naturaliza" a desigualdade e aceita produzir "gente" de um lado e "subgente" de outro (SOUZA, 2009, p. 25).

Nos condomínios fechados, pela restrição e orientação quanto à circulação, define-se quais indivíduos devem ser excluídos e vigiados, pois os muros imperiais funcionam como escudos "[...] cujo objetivo militar é impedir a entrada, ocultar a presença de recursos estratégicos e facilitar a observação do inimigo" (DUNKER, 2015, p. 36). Mas quem seriam os impostores inimigos? Os indivíduos que devem ser observados e impedidos de ingressar nos condomínios são os mesmos excluídos e abandonados da sociedade (SOUZA, 2018).

Mesmo que há décadas prevaleçam na sociedade discursos voltados à inclusão social, observa-se que na prática ocorre o oposto. A realidade dos incluídos socialmente, dos indivíduos privilegiados que não foram esquecidos ou marginalizados, defende que "[...] em nome da insegurança, da indeterminação, do estranhamento e de seus consequentes juízos de diferença que se formam muros, arenas e jardins, espaços protegidos no interior dos quais o conflito pode ser administrado" (DUNKER, 2015, p. 38). 
Para se proteger os ditos “cidadãos de bem” dos delinquentes (classe dominada, inferior, submissa e invisível), expressa-se a lógica do condomínio, com a exclusão do “[...] que está fora de seus muros; portanto, no fundo, não há nada para pensar na tensão entre esse local murado e seu exterior” (DUNKER, 2015. p. 36). O muro materializa “[...] uma estrutura de defesa, uma forma de determinação do espaço como território", apresenta-se "[...] como figura da indiferença, da exclusão e da segregação, contendo dentro de si a forma indeterminada de negação dos tempos da demanda" (DUNKER, 2015, p. 41-45).

A sistemática de venda dos condomínios gera ilusão de controle, por virem acompanhadas da "[...] promessa de distinção social que não se distingue de outras formas de autoexclusão social” (SILVA, 2007, n.p.). Nos condomínios seria possível alcançar a ordem social, pois nele estão inseridos apenas os escolhidos, há um síndico responsável pela gestão dos condôminos, que preza pela ordem e bem-estar de todos, “[...] são como aqueles antigos castelos em cartolina para recortar e colar, que montávamos quando crianças, só que em tamanho natural (DUNKER, 2015, p. 34).

Semelhantemente à falsa ideia de que os condomínios transmitem proteção social, temse os estabelecimentos prisionais, mas em lógicas opostas. Os condomínios prezam pela inclusão dos bons e acreditam que os seus muros imponentes são capazes de impedir o ingresso dos indivíduos maus, enquanto os estabelecimentos prisionais segregam os considerados maus, em celas precárias, para que a sociedade do lado de fora esteja segura. Ambas as descrições são formas que a sociedade encontrou para "limpar a cidade", formas de normalização, pois,

[...] as únicas duas coisas úteis que se espera e se deseja do "poder público" são que ele observe os "direitos humanos", isto é, que permita que cada um siga seu próprio caminho, e que permita que todos o façam em "paz" - protegendo a segurança de seus corpos e posses, trancando criminosos reais ou potenciais nas prisões e mantendo as ruas livres de assaltantes, pervertidos, pedintes e todo tipo de estranhos constrangedores e maus [...] (BAUMAN, 2011, n.p.).

Ao defender uma sociedade ideal, sem patologias ou precariedades que necessitariam ser enfrentadas, busca-se, constantemente, uma "limpeza" social, que podem ser compreendidas pelas lentes da exclusão. Essa é a lógica dos manicômios e a dos estabelecimentos prisionais, "[...] a segregação surge do fracasso em articular a diferença e a divisão" (DUNKER, 2015, p. 39). A legislação que rege a vida dos indivíduos passou a ser reconhecida como “[...] insensata, insuficiente e, não obstante, instrumentalizada em procedimentos normativos" (DUNKER, 2015, p. 38).

As prisões determinam uma forma de exclusão social. Nota-se que a maioria dos componentes dos estabelecimentos prisionais são aqueles indivíduos que estão do lado de fora 
dos condomínios fechados, são os abandonados e invisíveis, que vivem à margem da sociedade, em condições precárias e degradantes. Compreende-se a “[...] prisão como um mero exemplo dentre vários de uma estratégia geral de encobrimento da dominação social, sempre extremamente violenta, mas invisível na sua violência, sempre encoberta pelas 'belas palavras' da democracia” (SOUZA, 2009, p. 423).

Percebe-se, com isso, que os mal-estares da sociedade tendem a ficar isolados por muros. Desde o início da história da nação, os malquistos pela miséria, pela vagabundagem, pela loucura e pela criminalidade são impulsionados a viver e conviver juntos, em albergagem e aprisionamento (DUNKER, 2015). Além de já ter se demonstrado falha e insuficiente, sendo conhecidos “[...] todos os inconvenientes da prisão, sabe-se que é perigosa quando não inútil. E entretanto não 'vemos' o que pôr em seu lugar, ela é a detestável solução, de que não se pode abrir mão" (FOUCAULT, 1999, p. 261).

Um aspecto semelhante entre os condomínios e os estabelecimentos prisionais são as regras. Os condôminos seguem

"[...] regras extremamente severas e punições draconianas são estabelecidas para
pequenos atos infracionais, traço bizarramente idêntico ao que se verifica no interior
das prisões. Punição exemplar, punição espetacular. Tudo se passa como se a
permissividade, expressa pelo ideal, retornasse na forma de severidade em um
regramento insensato" (DUNKER, 2015, p. 56).

Tem-se a concepção de que nos condomínios, os “[...] transgressores, quando não eliminados, são enviados para outras galáxias, com o fim explícito de incitar revoltas, greves e perturbações estudantis" (DUNKER, 2015. p. 36). Raciocínio semelhante quando relatado sobre os transgressores legais, que pelo senso comum, devem ser julgados e condenados ao isolamento e às formas mais temíveis de vida, sem considerar o sofrimento, o abandono e a invisibilidade pretérita.

Os condomínios e as prisões se prestam para o diagnóstico do modelo de sociedade indiferente, individualista e privatizada, que só possibilita algum espaço de convivência pública nos playgrounds e nas quadras de tomar sol ou jogar futebol (DUNKER, 2015). Então, a liberdade, direito fundamental, é relativa, flexível e restringível. Não são todos os indivíduos que conseguem sentirem-se livres, por completo. Alguns, mesmo inexistindo barreiras, estão presos, pois “[...] sentir-se livre significa não experimentar dificuldade, obstáculo, resistência ou qualquer outro impedimento aos movimentos pretendidos ou concebíveis" (BAUMAN, 2011, n.p.). 
O projeto Panóptico de Jemery Bantham, utilizado por Michel Foucault, pode ser utilizado como uma metáfora do poder exercido sobre os corpos que impede a liberdade plena. No Panóptico, assim como na sociedade, os indivíduos estão

\begin{abstract}
“[...] presos ao lugar e impedidos de qualquer movimento, confinados entre muros grossos e densos e bem-guardados, e fixados a suas camas, celas ou bancadas, eles não podiam se mover porque estavam sob vigilância; tinham que se ater aos lugares indicados sempre porque não sabiam, e nem tinham como saber, onde estavam no momento seus vigias, livres para mover-se à vontade" (BAUMAN, 2011, n.p.).
\end{abstract}

A prisão é vista como um espaço central de "[...] produção de espaços de exclusão e anomia de um lado e na definição de condomínios de classificação diagnóstica flexível de outro" (DUNKER, 2015, p. 21). Pela falsa concepção de que ao isolar-se com os considerados semelhantes, ocorrerá a segurança, pois

[...] a relação de amigo-inimigo é indeterminada. O outro pode ser aprisionado, retido em cativeiro, devorado e, mesmo assim, não se saberá quem exatamente ele é, o que no inimigo foi devorado e, reciprocamente, que méritos devem ser atribuídos ao matador nessa operação (DUNKER, 2015. p. 198).

Conforme o exemplo de amigo-inimigo, no qual não importa saber quem é o "matador", a sociedade observa as patologias, tem ciência de que elas precisam ser enfrentadas, mas não deseja saber como é o tratamento e se há possibilidade de "cura". Independente dos meios utilizados, os indivíduos desejam resultados e não explicações. Ao compreender que as desigualdades sociais representam uma patologia social, e que um dos seus sintomas é a criminalidade, que acaba por causar sofrimentos individuais e coletivos, verifica-se que, similar à lógica do condomínio, utiliza-se como tratamento o isolamento, mas sem qualquer preocupação com as causas da doença. Entretanto, a exclusão não se mostra eficaz, pelo contrário, determina que os sintomas patológicos aumentem e que seja estabelecida uma epidemia de difícil tratamento.

\title{
Considerações finais
}

No intento de responder à indagação se o encarceramento pode ser considerado uma forma de tratamento adequado para o sintoma patológico do crescente aumento da criminalidade em razão da desigualdade social, buscou-se apoio em Dunker a fim de ressaltar semelhanças entre realidades opostas, quais sejam, os condomínios e as prisões.

Paira uma sensação de que, na atual quadra histórica, perdeu-se o controle das relações sociais, razão pela qual abunda uma patologia social representada pelo crescente aumento da criminalidade, que necessita de tratamento para se restaurar a normalidade. $O$ crescente 
aumento da criminalidade reproduz uma anormalidade social e, pelo fato de a sociedade clamar por resultados eficazes e céleres, utiliza-se o encarceramento como forma de tratamento da patologia.

Na estrutura da sociedade hodierna, evidente a divisão de classes, na qual nem todos os indivíduos detêm as mesmas oportunidades, de modo que o sofrimento, como sintoma decorrente da patologia social desigualdade, maltrata os mais pobres. A criminalidade, como consequência sintomática da patologia social das desigualdades, alcançou proporções alarmantes, e embora maltrate mais diretamente os do andar de baixo, desequilibra a vida em sociedade.

A simplificação do tratamento disponibilizado para a anomia social causa danos irreparáveis. O encarceramento, assim como a autoexclusão (pelos condomínios) são formas simplistas de tamponar a causa do problema social da insegurança. Por analogia, pode-se dizer que o encarceramento em massa produz os mesmos efeitos que os "Copiadores de Receitas" produzem, ou seja, sedam os indivíduos na tentativa de esconder os reais problemas que afligem a sociedade.

O tratamento disponibilizado pelo sistema para os sintomas patológicos provocados pela desigualdade social não gera resultados satisfatórios. Normalmente, os encarcerados são os indivíduos já excluídos da sociedade quando em liberdade, porém, nada obstante, o tratamento ofertado pela segregação, em estabelecimentos prisionais em condições precárias e degradantes, ao invés de tratar, acaba por piorar os sintomas patológicos.

A realidade que assola a contemporaneidade é diferente dos belos discursos democratas de igualdade, pois o encarceramento seletivo que ocorre, aparentemente, tem apenas o fim de "limpar" a sociedade visualmente. As prisões não são um espaço de ressocialização, mas um “esconderijo dos maus", os quais são afastados do convívio das "pessoas de bem" por algum tempo, traduzindo uma falsa sensação de segurança e assinando um atestado de incapacidade, do poder público e da sociedade, de enfrentar os problemas estruturais produtores da criminalidade.

\section{Referências}

ARAUJO, Izaura. Emile Durkheim. Disponível em: https://escolaeducacao.com.br/emiledurkheim/. Acesso em: 08 dez. 2019.

BAUMAN, Sygmunt. Modernidade Líquida. Rio de Janeiro: Zahar, 2011. Edição eletrônica: julho 2011. 
BOURDIEU, Pierre. O poder Simbólico. Lisboa: Difel, 1989.

CAMPELLO, Filipe. Crítica e Patologia social: ambivalências da relação entre psicanálise e teoria social. p. 3 - 27. Dissertatio: 2017.

MATTA, Roberto da. Carnavais, malandros e heróis: para uma sociologia do dilema brasileiro. 6. ed. Rio de Janeiro: Rocco, 1997.

DUNKER, Christian Ingo Lenz. Mal-estar, sofrimento e sintoma: uma patologia do Brasil entre muros. 1. ed. São Paulo: Boi e tempo, 2015.

DURKHEIM, Emile. As regras do método sociológico. Tradução Paulo Neves. 3. ed. São Paulo: Martins Fontes, 2007.

FANON, Frantz. Os condenados da terra. São Paulo: Editora Ulissia, 2015.

FOUCAUlT, Michel. Vigiar e Punir: nascimento da prisão. Trad. Raquel Ramalhete. 20. ed. Petrópolis: Vozes, 1999.

FREUD, Sigmund. O mal-estar na cultura. Tradução Renato Zwick. Porto Alegre/RS: L\&PM, 2010.

LEVANTAMENTO NACIONAL DE INFORMAÇÕES PENITENCIÁRIAS.

Departamento Penitenciário Nacional Ministério da Justiça e Segurança Pública. 2017.

Disponibilizado em: http://depen.gov.br/DEPEN/depen/sisdepen/infopen. Acesso em: 04 dez. 2019.

MANZI, Ronaldo. Um sintoma de patologia do social: a homofobia. Revista educação, V.12. n. 1, 2017.

SAFARIE, Vladimir; DA SILVA JR, Nelson; DUNKER, Christian. Patologias do Social: Arqueologia do sofrimento psíquico. 1. ed. Belo Horizonte: autentica editora, 2018.

SILVA, Filipe Carreira da. Confiança e Medo na Cidade. Anál. Social, Lisboa, n. 183, p.647651, abr. 2007.

SIMIM, Thiago Aguiar. Invisibilidade social a partir do filme "O som ao redor": uma análise honnethiana das patologias sociais no Brasil. Ciências Sociais, São Leopoldo, jan./abr. de 2015, p. 52-60.

SOUZA, Jesse. Ralé Brasileira: quem é e como vive. Belo Horizonte, Editora UFMG, 2009.

SOUZA, Jesse. Subcidadania Brasileira: para entender o país além do jeitinho brasileiro. Rio de Janeiro: LeYa, 2018.

VERONESE, Luciane Gheller; VERONESE, Osmar. Infância e cidadania na ressignificação do espaço público. Anais do VI Congresso Brasileiro de Processo Coletivo e Cidadania da Universidade de Ribeirão Preto, n. 6, p. 627-646, out/2018. Disponível em: http://revistas.unaerp.br/cbpcc/article/view/1245/1055. Acesso em: 14 abr. 2020. 
VERONESE, Osmar; SILVA, Daiane Specht Lemos da. Entre celas: o encarceramento como sintoma de uma sociedade patológica

VERONESE, Luciane Gheller; VERONESE, Osmar. Saúde Mental no Brasil: impasses e horizontes de uma Política Pública. Direitos Culturais, Santo Ângelo, v. 12, p. 75-90, jan./abr. 2017. 